\title{
Clinicohaematological \& Aetiological Profile of Bicytopenic / Pancytopenic Children in Dehradun, India - A 5-Year Study
}

\author{
Neelima Bahal ${ }^{1}$, Avneesh Malviya ${ }^{2}$, Sana Ahuja ${ }^{3}$ \\ 1,2,3 Department of Pathology, Shri Guru Ram Rai Institute of \\ Medical \& Health, College of Nursing, Dehradun, Uttarakhand, India.
}

\section{ABSTRACT}

\section{BACKGROUND}

Cytopenia (bicytopenia / pancytopenia) in paediatric age group patients presents with variable clinical features from pallor, fever to organomegaly. Causes vary from megaloblastic anaemia to fatal leukaemias. The purpose of the study was to evaluate the etiological and clinico-haematological profile in children with bicytopenia and pancytopenia.

\section{METHODS}

The present retrospective study was carried out in the section of haematology, Department of Pathology of Shri Guru Ram Rai Institute of Health and Medical Sciences, Dehradun. All paediatric cases (up to 18 yrs.) with bone marrow examination, that were presented as bicytopenia or pancytopenia by routine haematological investigations were included in the study.

\section{RESULTS}

A total of 126 cases were included in the study, out of which, bone marrow aspiration was done in all 126 cases and trephine biopsy was done in only 78 cases. In our study, bicytopenia and pancytopenia was seen in $57.9 \%$ and $42.1 \%$ cases respectively. Most cases were recorded in $2^{\text {nd }}$ decade. Pallor and fever were frequently observed clinical features in both cytopenias. Splenomegaly, lymphadenopathy and hepatomegaly were observed more in bicytopenia $34.2 \%, 28.8 \%$ and $27.4 \%$ respectively). Bleeding and petechial rash were more common in pancytopenia (30.2 $\%$ and $20.8 \%$ respectively). Anaemia and thrombocytopenia (67.1\%) were commonest combinations of bicytopenia followed by anaemia and leucopenia (26.0 $\%)$ and thrombocytopenia and leucopenia (6.8\%).

\section{CONCLUSIONS}

Bone marrow aspiration and trephine biopsy are important diagnostic tools in evaluating the cases of cytopenia. Both procedures are complementary to each other.

\section{KEY WORDS}

Bicytopenia, Pancytopenia, Megaloblastic Anaemia, Leukemia, Children
Corresponding Author: Dr. Avneesh Malviya, F3 Sgrr Campus

Patel Nagar, Dehradun, Uttarakhand, India.

E-mail: avneeshmalviya@gmail.com

DOI: $10.14260 /$ jemds/2021/284

How to Cite This Article:

Bahal N, Malviya A, Ahuja S. Clinicohaematological \& aetiological profile of bicytopenic / pancytopenic children in Dehradun, India - a 5-year study. J Evolution Med Dent Sci 2021;10(18): 1347-1352, DOI:

$10.14260 / j e m d s / 2021 / 284$

Submission 25-05-2020,

Peer Review 01-03-2021,

Acceptance 08-03-2021,

Published 03-05-2021.

Copyright (C) 2021 Neelima Bahal et al. This is an open access article distributed under Creative Commons Attribution License [Attribution 4.0 International (CC BY 4.0)] 


\section{BACKGROUND}

Sir William Harvey described blood as 'the fountain of life and the primary seat of soul. The marrow of our bones is the seedbed of our blood'.1 Careful assessment of the blood elements is often the first step in assessment of haematological function and diagnosis.

Cytopenia is not a diagnosis but is a presentation of some underlying general medical or primary haematological disorder. ${ }^{2}$ Pancytopenia and bicytopenia is defined as the decrease in the number of all the three cell lineages and two cell lineages of the blood below the normal reference values respectively. There is a considerable overlap between the causes and diagnostic approach of bicytopenia and pancytopenia. $^{2}$

The incidence of various disorders causing cytopenia varies due to geographic distribution and genetic disturbances. ${ }^{3}$ Alteration in the peripheral blood counts due to cytopenia is commonly encountered in paediatric population. Presence of pancytopenia usually indicates the presence of either a bone marrow failure syndrome or acute malignancy particularly when associated with lymphadenopathy or organomegaly. 4

Presenting symptoms of cytopenia are often attributable to anaemia or thrombocytopenia. Leucopenia is uncommon but can be a very serious threat to life. 5 Detailed history, physical examination provides valuable information for the work up of cytopenic patients.

Bone marrow examination is an extremely important and effective way of diagnosing and evaluating haematologic and metastatic neoplasm as well as non-haematological disorders responsible for cytopenia. Bone marrow examination involves the study of bone marrow aspirates, imprint smears and trephine biopsy. These three procedures are complementary to each other and superiority of one method over the other depends on the specific disease process. ${ }^{6}$

In India, the causes of pancytopenia are not well defined. Previous studies conducted in India stress the importance of megaloblastic anaemia as the major cause of pancytopenia.4,7 The current study intends to evaluate the various causes of bicytopenia and pancytopenia in paediatric patients and their clinico-haematological correlations.

\section{METHODS}

The retrospective study was carried out in the section of haematology, Department of Pathology of Shri Guru Ram Rai Institute of Health and Medical Sciences, Dehradun. This is a retrospective study and all paediatric cases (up to $18 \mathrm{yrs}$.) that were diagnosed as bicytopenia or pancytopenia by routine haematological investigations, of whom bone marrow examination were done, were included in the study.

These cases were from outdoor patient department (OPD) and indoor patient department (IPD). Relevant clinical history and examination findings along with routine haematological, biochemical and serological investigations were recorded on a pretested proforma. The research proforma was vetted and approved by the institutional research and ethical committee. A total of 126 cases were examined from January 2015 to December 2019. Sample size was taken based on the convenience of the study. Prior written informed consent was taken from the patient. Bone marrow aspiration was done in all 126 cases. However, bone marrow biopsy could be done in 78 patients.

In all cases the inclusion criteria based on routine haematological investigations, either singly or in combination were as follows-

- Haemoglobin - $<10 \mathrm{~g} / \mathrm{dl}$

- Total leucocyte count $-<4000 / \mu \mathrm{l}$

- Platelet count $-<1.0$ lac $/ \mu \mathrm{l}$

Blood sample was collected in ethylenediamine tetra acetic acid (EDTA) vacutainer using all aseptic precautions. In all the cases of cytopenia, complete blood counts were done by automated cell counter (Sysmex KX21). Platelet counts were counter checked by peripheral smears. Bone marrow aspirate smears were stained with May Grunwald-Giemsa (MGG), myeloperoxidase (MPO), periodic acid-Schiff PAS and Perl's Prussian blue stain as required. Trephine biopsy were stained with $\mathrm{H} \&$ E stain.

\section{Statistical Analysis}

The Statistical Package for Social Science (SPSS) version 20 was used for statistical analysis. The data was summarised using frequency and percentage.

\section{RESULTS}

According to the criteria setup for cytopenia, a total of 126 cases were taken up for the study. Bone marrow aspiration was done in all 126 cases, out of this trephine biopsy was done only in 78 cases. All the relevant data was recorded on the proforma and routine haematological investigations that were done, were analysed. The results of the analysis are given in the following tables.

\begin{tabular}{|ccc|}
\hline Cytopenia & Total Number of Cases & Percentage \\
Pancytopenia & 53 & 42.1 \\
Bicytopenia & 73 & 57.9 \\
Total & 126 & 100 \\
\hline Table 1. Distribution of Cases of Cytopenia $(\boldsymbol{N}=\mathbf{1 2 6})$ \\
\hline
\end{tabular}

Pancytopenia was seen in 53 cases (42.1\%) and bicytopenia was seen in 73 cases (57.9\%) of cytopenia (Table I).

\begin{tabular}{|ccc|}
\hline Sex & Total Number of Cases & Percentage \\
Male & 64 & 50.8 \\
Female & 62 & 49.2 \\
Total & $\mathbf{1 2 6}$ & $\mathbf{1 0 0}$ \\
\hline \multicolumn{2}{|c|}{ Table 2. Distribution of All Cases of Cytopenia } \\
& According to Sex (N=126) \\
\hline
\end{tabular}

Table II shows the distribution of cases according to sex of the patient. Maximum number of cases, (64 cases, $50.8 \%$ ) were seen amongst males, while females accounted for 62 cases (49.2\%). Thus, these findings show almost equal numbers of cases in both sexes.

Table III shows distribution of clinical features of the cases. Rarely a case is presented with a single clinical feature. Most 
of the cases were presented with combination of two to three or more signs and symptoms. As per the frequency of clinical features, in both bicytopenia and pancytopenia pallor was seen in maximum number of cases in 55 cases (75.3\%) and 45 cases $(84.9 \%)$ followed by fever in 52 cases $(71.2 \%)$ and 40 case $(75.5 \%)$ respectively.

\begin{tabular}{|ccc|}
\hline Signs and Symptoms & Bicytopenia & Pancytopenia \\
\hline Pallor & $\mathrm{N}=73$ & $\mathrm{~N}=53$ \\
Fever & $55(75.3)$ & $45(84.9)$ \\
Splenomegaly & $52(71.2)$ & $40(75.5)$ \\
Weakness & $25(34.2)$ & $11(20.8)$ \\
Hepatomegaly & $19(26.0)$ & $14(26.4)$ \\
\hline Petechial rash & $20(27.4)$ & $8(15.1)$ \\
Bleeding manifestations & $10(13.7)$ & $11(20.8)$ \\
Lymphadenopathy & $15(20.5)$ & $16(30.2)$ \\
Bone / body pain & $21(28.8)$ & $7(13.2)$ \\
\hline Jaundice & $9(12.3)$ & $5(9.4)$ \\
\hline Table 3. Distribution of Cases According to Frequency of Clinical \\
Features (Values in Parentheses are in Percentage)
\end{tabular}

\begin{tabular}{|c|c|c|c|c|}
\hline & & Bicytopenia & Pancytopenia & $\begin{array}{c}\text { Total } \\
\text { Number } \\
\text { of Cases }\end{array}$ \\
\hline \multirow{5}{*}{$\begin{array}{l}\text { Haemoglobin } \\
\text { (g / dl) }\end{array}$} & $<6$ & $28(38.4)$ & $25(47.2)$ & $53(42.1)$ \\
\hline & $6-8$ & $24(32.9)$ & $14(26.4)$ & $38(30.2)$ \\
\hline & $8-10$ & $16(21.9)$ & $14(26.4)$ & 30 (23.8) \\
\hline & $\geq 10$ & $5(6.8)$ & - & $5(4.0)$ \\
\hline & Total & 73 & 53 & 126 \\
\hline \multirow{5}{*}{$\begin{array}{c}\text { Platelet } \\
\text { count }(/ \mu \mathrm{l})\end{array}$} & $<20000$ & $10(13.7)$ & $11(20.8)$ & $21(16.7)$ \\
\hline & $20000-50000$ & 30 (41.1) & $20(37.7)$ & $50(39.7)$ \\
\hline & $50000-100000$ & $14(19.2)$ & $22(41.5)$ & $36(28.6)$ \\
\hline & $\geq 100000$ & $19(26.0)$ & - & 19 (15.1) \\
\hline & Total & 73 & 53 & 126 \\
\hline \multirow{4}{*}{$\begin{array}{l}\text { Leucocyte } \\
\text { Count }(/ \mu \mathrm{l})\end{array}$} & $<1000$ & $1(1.4)$ & $1(1.9)$ & $2(1.6)$ \\
\hline & $1000-4000$ & $23(31.5)$ & $52(98.1)$ & $75(59.5)$ \\
\hline & $\geq 4000$ & 49 (67.1) & - & 49 (38.9) \\
\hline & Total & 73 & 53 & 126 \\
\hline \multicolumn{5}{|c|}{$\begin{array}{c}\text { Table 4. Distribution of Haemoglobin Values, Platelet Count and } \\
\text { Leucocyte Count in Different Cases of Cytopenia (Values in } \\
\text { Parentheses are in Percentage) }\end{array}$} \\
\hline
\end{tabular}

\begin{tabular}{|c|c|c|c|}
\hline Aetiology & Bicytopenia & Pancytopenia & Total \\
\hline Normoblastic marrow & $9(12.3 \%)$ & $7(13.2 \%)$ & $16(12.7 \%)$ \\
\hline Megaloblastic marrow & $21(28.8 \%)$ & $21(39.6 \%)$ & $42(33.3 \%)$ \\
\hline Hypoplastic marrow & $9(12.3 \%)$ & $12(22.6 \%)$ & $21(16.7 \%)$ \\
\hline Acute leukemia & $18(24.7 \%)$ & $9(17.0 \%)$ & $27(21.4 \%)$ \\
\hline Lymphoproliferative disorder & $1(1.4 \%)$ & $1(1.9 \%)$ & $2(1.6 \%)$ \\
\hline $\begin{array}{l}\text { Idiopathic thrombocytopenia } \\
\text { purpura }\end{array}$ & $8(11.0 \%)$ & $0(0 \%)$ & $8(6.3 \%)$ \\
\hline Visceral leishmaniasis & $1(1.4 \%)$ & $1(1.9 \%)$ & $2(1.6 \%)$ \\
\hline Inadequate & $3(4.1 \%)$ & $2(3.8 \%)$ & $5(3.9 \%)$ \\
\hline Nutritional anaemia & $2(2.7 \%)$ & $0(0 \%)$ & $2(1.6 \%)$ \\
\hline Miscellaneous & $1(1.4 \%)$ & $0(0 \%)$ & $1(0.8)$ \\
\hline Total & 73 & 53 & 126 \\
\hline \multicolumn{4}{|c|}{$\begin{array}{c}\text { Table 5. Aetiologies of Bicytopenia \& Pancytopenia } \\
\text { (Values in Parentheses are in Percentage) }\end{array}$} \\
\hline
\end{tabular}

Table IV A shows majority (42.1\%, $\mathrm{N}=53$ ) of cases having haemoglobin less than $6 \mathrm{~g} / \mathrm{dl}$. Considering a value of $10 \mathrm{~g} / \mathrm{dl}$ as a cut off value of anaemia, anaemia was seen in $96.0 \%$ (N = 121) cases of cytopenia.

Table IV B shows that the majority ( $68.3 \%$ ) of cases were observed to have platelet count between 20000 and 100000 / $\mu \mathrm{l}$ with only $16.7 \%$ cases having platelet count less than 20000 / $\mu$ l. Thrombocytopenia was observed in $86.5 \%$ cases $(\mathrm{N}=$ 109) in this study, taking a value of $100000 / \mu \mathrm{l}$ as the cut off for thrombocytopenia.
Table IV C. shows that $59.5 \%$ of cases were seen to have leucocyte count between 1000 and $4000 / \mu$ l. Only $1.6 \%$ of cases had leucocyte count less than $1000 / \mu$ l. Leucopenia was seen in $61.1 \%(\mathrm{~N}=77)$ cases in this study, taking $4000 / \mu \mathrm{l}$ as the cut off for leucopenia.

Table $\mathrm{V}$ shows that megaloblastic marrow was predominant cause in both bicytopenia and pancytopenia in $28.8 \%$ and $39.6 \%$ respectively followed by acute leukemia in $24.7 \%$ of bicytopenic cases while hypoplastic marrow (22.6 $\%)$ was the second most common cause of pancytopenia. Idiopathic thrombocytopenia purpura (ITP) was observed in $11.0 \%$ cases of bicytopenia.

\begin{tabular}{|c|c|c|c|c|c|c|}
\hline \multirow{2}{*}{$\begin{array}{l}\text { Age } \\
\text { Group }\end{array}$} & \multicolumn{3}{|c|}{ Bicytopenia $(\mathrm{N}=73)$} & \multicolumn{3}{|c|}{ Pancytopenia $(\mathrm{N}=53)$} \\
\hline & $\begin{array}{l}\text { Number } \\
\text { of Cases }\end{array}$ & $\begin{array}{c}\text { Most } \\
\text { Common } \\
\text { Cause }\end{array}$ & $\begin{array}{l}\text { Second } \\
\text { Most } \\
\text { Common } \\
\text { Cause }\end{array}$ & $\begin{array}{l}\text { Number } \\
\text { of Cases }\end{array}$ & $\begin{array}{l}\text { Most } \\
\text { Common } \\
\text { Cause }\end{array}$ & $\begin{array}{l}\text { Second } \\
\text { Most } \\
\text { Common } \\
\text { Cause }\end{array}$ \\
\hline$\leq 5 \mathrm{yr}$ & $21(28.8)$ & $\begin{array}{c}\text { Acute leukemia } \\
\text { (28.6) }\end{array}$ & $\begin{array}{l}\text { Hypoplastic } \\
\text { marrow (19) }\end{array}$ & $12(22.6)$ & $\begin{array}{c}\text { Acute } \\
\text { leukemia, } \\
\text { Hypoplastic } \\
\text { marrow, } \\
\text { Megaloblastic } \\
\text { anaemia (25 } \\
\text { each) }\end{array}$ & $\begin{array}{c}\text { Normoblastic } \\
\text { marrow, } \\
\text { Kala-Azar } \\
\text { (8.3 each) }\end{array}$ \\
\hline $\begin{array}{c}6-10 \\
\text { yr. }\end{array}$ & $9(12.3)$ & $\begin{array}{l}\text { Acute leukemia, } \\
\text { Hypoplastic } \\
\text { marrow, } \\
\text { Megaloblastic } \\
\text { anaemia, ITP } \\
\text { (22.2 each) }\end{array}$ & $\begin{array}{c}\text { Normoblastic } \\
\text { marrow } \\
(11.1)\end{array}$ & $5(9.4)$ & $\begin{array}{c}\text { Acute } \\
\text { leukemia, } \\
\text { Hypoplastic } \\
\text { marrow ( } 40 \\
\text { each) }\end{array}$ & $\begin{array}{l}\text { Normoblastic } \\
\text { marrow (20) }\end{array}$ \\
\hline $\begin{array}{c}11-14 \\
\text { yr. }\end{array}$ & $18(24.7)$ & $\begin{array}{l}\text { Megaloblastic } \\
\text { marrow (38.9) }\end{array}$ & $\begin{array}{l}\text { Acute } \\
\text { leukemia } \\
(33.3)\end{array}$ & $11(20.8)$ & $\begin{array}{l}\text { Megaloblastic } \\
\text { marrow (45.5) }\end{array}$ & $\begin{array}{l}\text { Hypoplastic } \\
\text { marrow } \\
(36.4)\end{array}$ \\
\hline $\begin{array}{c}15-18 \\
\text { yr. }\end{array}$ & 25 (34.2) & $\begin{array}{l}\text { Megaloblastic } \\
\text { marrow (36) }\end{array}$ & $\begin{array}{c}\text { Acute } \\
\text { leukemia } \\
(16)\end{array}$ & $25(47.2)$ & $\begin{array}{l}\text { Megaloblastic } \\
\text { marrow (52) }\end{array}$ & $\begin{array}{l}\text { Normoblastic } \\
\text { marrow (20) }\end{array}$ \\
\hline \multicolumn{7}{|c|}{$\begin{array}{c}\text { Tables 6. Aetiologies of Bicytopenia \& Pancytopenia, Age Group Wise } \\
\text { (Values in Parentheses are in Percentage) }\end{array}$} \\
\hline
\end{tabular}

\section{DISCUSSION}

It was observed in this study that relevant clinical history, physical examination findings along with routine haematological parameters were needed for evaluating the bone marrow aspiration smear and biopsy sections to arrive at a conclusive diagnosis.

Both bone marrow aspiration and biopsy are complementary to each other to give the correct diagnosis. Gupta et al. in their study have also reported that bone marrow aspiration and trephine biopsy are complementary to each other to arrive at a definitive diagnosis. ${ }^{6}$ This was observed in our study also and was evident in the following cases: An inadequate aspiration was diagnosed as lymphoproliferative disorder on trephine biopsy. Similarly, a case of Plasmodium falciparum infection presenting as pancytopenia was diagnosed by peripheral blood film examination. It was not evident on the bone marrow examination, signifying the complementary role of trephine biopsy and peripheral blood film examination to arrive at a diagnosis.

The incidence of pancytopenia and bicytopenia in our study was $42.1 \%(\mathrm{~N}=53)$ and $57.9 \%(\mathrm{~N}=73)$ cases respectively. A study by Bhatnagar et al. from India reported pancytopenia in $54.5 \%$ cases and bicytopenia seen in $45.5 \%$ cases. ${ }^{4}$ Ayub et al. found almost equal number of cases presenting as pancytopenia and bicytopenia. ${ }^{8}$ However, the observations of Naseem et al. in their study were very different 
from the results of present study with pancytopenia seen in 40 $\%$ cases and bicytopenia seen in $17 \%$ cases. $^{2}$ This difference in the incidence of cytopenia can be attributed to difference in methodology, selection of diagnostic criteria, socio-economic status and nutritional status of cases included in the study.

The present study shows 64 cases in male and 62 cases in females giving almost equal incidence with male to female ratio of 1.03:1. Other studies conducted in India and other countries observed slightly more male preponderance.5,9,10,11

The youngest patient was 7 months old. The highest incidence of cytopenia was observed in the 2nd decade $\{(79$ cases, $62.7 \%$ ) (Bicytopenia vs. Pancytopenia: $54.4 \%$ vs. 45.6 $\%$ )\}. Patients up to 10 years of age constituted $37.3 \%$ cases (n =47) (Bicytopenia vs Pancytopenia: $63.8 \%$ vs. $36.2 \%$ ). $30 \%$ pancytopenia observed by Gayathri et al. in paediatric age group ${ }^{11}$ Khodke et al. also found maximum patients (44\%) in the age group of $12-30$ years. ${ }^{7}$ Negi et al. found $48 \%$ cases in the age range of $11-30$ years. ${ }^{12}$

The importance of history, clinical features and physical signs in evaluating the cases of cytopenia has been emphasized. The most common presenting clinical feature in the cases included in our study in both bicytopenia and pancytopenia was pallor seen in 55 cases (75.3\%) and 45 cases $(84.9 \%)$ followed by fever in 52 cases $(71.2 \%)$ and 40 case $(75.5 \%)$ respectively.

Splenomegaly (34.2\%), lymphadenopathy (28.8\%) and hepatomegaly (27.4\%) were more frequent in Bicytopenia than pancytopenia $(20.8 \%, 13.2 \%$ and $15.1 \%$ respectively).

Bleeding (30.2\%) and petechial rash (20.8\%) were more frequent in pancytopenia than bicytopenia $(20.5 \%$ and $20.8 \%$ respectively).

Most of studies studied cytopenia in combination or only pancytopenia, however Naseem et al. studied separately although frequency varies. ${ }^{2}$ Similar clinical features have been reported in other studies, although the frequency varies. The difference in the frequency of clinical features can be attributed to geographic variation, genetic makeup of the patient and the haematological parameter being predominantly affected in cytopenia.

Considering the etiological basis of bicytopenia in our study, megaloblastic marrow was predominant cause seen in $28.8 \%(\mathrm{~N}=21)$ followed by acute leukemia in $24.7 \%(\mathrm{~N}=18)$, hypoplastic and normoblastic marrow in $12.3 \%(\mathrm{~N}=9$ each) and ITP in $11 \%(\mathrm{~N}=8)$, however acute leukemia (29.2\%) was most common cause up to 14yrs. Of leukaemias, acute lymphoblastic leukaemia (ALL) was predominantly seen in 16 cases while 2 case were acute myeloid leukaemia (AML).

Megaloblastic anaemia was most common aetiology of pancytopenia in our study in $39.6 \%(\mathrm{~N}=21)$ followed by hypoplastic marrow in $22.6 \%(\mathrm{~N}=12)$, acute leukemia in 17.0 $\%(\mathrm{~N}=9)$ and normoblastic marrow in $13.2 \%(\mathrm{~N}=7)$, however hypoplastic marrow (32.1\%) was most common cause up to 14 yrs.

Infection (visceral Leishmaniasis) was found in two patients one each in both cytopenia.

In most of the literature, only pancytopenia was studied. Bicytopenia and pancytopenia have been studied separately in only very few studies.

The commonest cause of pancytopenia reported in various studies throughout the world is aplastic anemia.2,13,14,15 Bhatnagar et al. also reported megaloblastic anaemia as a cause of pancytopenia in $28 \%$ cases followed by aplastic anaemia in $21 \%$ cases. $^{4}$

Analysis of various studies shows that the most common cause of pancytopenia in Asian countries is either aplastic anaemia or megaloblastic anaemia. Neoplastic conditions as the most common cause of pancytopenia is seen more commonly in western countries. Higher incidence of megaloblastic anaemia can be attributed to low socioeconomic status, poor hygiene, inadequate nutrition and some cultural taboos. A high frequency of aplastic anaemia can be related to environmental factors such as exposure to toxic chemicals rather than genetic factors. Farming being a major occupation in Indian subcontinent leading to increased exposure to pesticides also contributes to aplastic anaemia. Easy availability of over-the-counter medicines can also lead to increased risk of aplastic anaemia. All these risk factors are not seen in the western countries making neoplastic conditions as a common cause of pancytopenia rather than megaloblastic anaemia or aplastic anaemia.

Acute leukemia was the third most common cause of pancytopenia, seen in $16.98 \%(\mathrm{~N}=9)$ cases in our study. Bhatnagar et al. Gupta et al. Chhabra et al. and Naseem et al. observed leukemia as the second most common cause of pancytopenia and seen in $21 \%, 25 \%, 25.2 \%$ and $26.6 \%$ cases respectively. $4,16,17,2$ It could be due to types of patients included in study, both non-referral and referral

The incidence of other marrow infiltrative disorders like lymphoproliferative disorders was $1.9 \%$ of cases in this study. This was somewhat lower when compared to other studies in Indian subcontinent. Study by Chhabra et al. from India have shown lymphoma as a cause in $3 \%$ of the cases of pancytopenia. ${ }^{17}$

Leishmaniasis was seen to be the cause of pancytopenia in $1.9 \%$ cases in the present study. Naseem et al. Anwar Zeb Jan et al. and Jha et al. reported almost slightly similar incidence of leishmaniasis in $2.9 \%, 2.9 \%$ and $2.7 \%$ of the cases of pancytopenia respectively. $2,18,15$ A higher percentage of $14 \%$ was observed by Khodke et al. in their study, where all of the cases were from Bihar. ${ }^{7}$ It has been seen that leishmaniasis is a disease of Bihar, Bengal and areas adjoining. However, patients included in the present study were mostly natives of Uttarakhand with no history of travel to endemic areas leading to a lower incidence of leishmaniasis in the present study.

Normoblastic marrow was seen in $12.70 \%$ cases $(\mathrm{N}=16)$ of cytopenia in our study. Naseem et al. observed normoblastic marrow in $9.98 \%$ cases. $^{2}$ The finding of a normoblastic marrow in cases of cytopenia can be due to ineffective haematopoiesis or peripheral sequestration. These cases could represent an early stage of cytopenia or could be cases of refractory cytopenia. Patients were advised to remain in follow up so that any kind of progression could be easily identified.

The interpretation of this study is that megaloblastic anaemia, acute leukemia and hypoplastic marrow can be present either as pancytopenia or bicytopenia. However, it was observed that megaloblastic anaemia and hypoplastic marrow present more commonly as pancytopenia while acute leukemia usually presents as bicytopenia. More frequent association of leukemia with bicytopenia was also observed by Nassem et al. in their study where bicytopenia was associated with malignant conditions in $69.5 \%$ cases as compared to 26.6 $\%$ cases of pancytopenia, which is relatively higher as 
compared to findings in our study. ${ }^{2}$ This signifies that although pancytopenia is taken with greater clinical concern than bicytopenia, timely evaluation of bicytopenia is also very important. Another Indian study by Bhatnagar et al. observed similar results regarding the frequent association of leukemia with bicytopenia. ${ }^{4}$ They observed $21 \%$ cases of leukemia presenting as pancytopenia and $23 \%$ cases presenting as bicytopenia. Presentation of aplastic anaemia was seen as pancytopenia in $20 \%$ cases, which is similar to our findings, and as bicytopenia in $33 \%$ cases which is contrary to the findings in this study.

Although the haematological parameters are usually nonspecific in many cases and show a considerable overlap, they do give diagnostic clues for evaluation of cases of cytopenia.

In cytopenia, majority of cases (91 cases, $72.2 \%$ ) had haemoglobin values less than $8 \mathrm{~g} / \mathrm{dl}$ with $42.1 \%(\mathrm{~N}=53)$ cases having haemoglobin less than $6 \mathrm{~g} / \mathrm{dl}$.

In pancytopenia and bicytopenia most cases were noted with haemoglobin less than $6 \mathrm{gm} / \mathrm{dl} 47.2 \%(\mathrm{~N}=25)$ and $38.4 \%(\mathrm{~N}=28)$ respectively.

In cytopenia, $61.1 \%$ of cases $(\mathrm{N}=75)$ had leucocyte count between 1000 and $4000 / \mu \mathrm{l}$.

In bicytopenia, $32.9 \%$ of cases $(\mathrm{N}=24)$ had leucocyte count less than $4000 / \mu \mathrm{l}$.

In cytopenia, our study reported $68.3 \%(\mathrm{~N}=86)$ cases having platelet count between 20000 to 100000 / $\mu$ l with only $16.7 \%$ cases $(\mathrm{N}=21)$ having severe thrombocytopenia with platelet count below $20000 / \mu \mathrm{l}$.

The range of the haematological parameters observed in this study was almost similar to that seen in some recent studies by Negi et al. and Javalgi et al. in both children and adults. ${ }^{12,10}$ The variation in the range of haematological parameters can be attributed to the inclusion of cases of bicytopenia, only paediatric group in the present study as the other parameters could have a normal or more than the normal value.

Anaemia was seen in $96.0 \%$ cases $(\mathrm{N}=121)$ followed by thrombocytopenia in $84.9 \%$ cases $(\mathrm{N}=107)$ and leucopenia in $61.1 \%$ cases $(\mathrm{N}=77)$. This finding suggests that in cases of cytopenia, leucopenia is less common finding or is seen in the subsequent course of disease as also observed by Naseem, Khodke et al. from India and Ayub et al. from Pakistan respectively. $2,7,8$

In the present study, thrombocytopenia and anaemia were the commonest form of bicytopenia seen in $67.1 \%$ cases $(\mathrm{N}=$ 49) followed by anaemia and leucopenia in $26.0 \%$ cases $(\mathrm{N}=$ 19) and thrombocytopenia and leucopenia in $6.8 \%$ cases $(\mathrm{N}=$ 5). Our results correlate with another study done by Naseem et al. on paediatric patients, where they reported anaemia with thrombocytopenia to be the commonest bicytopenia seen in $77.5 \%$ cases and leucopenia with thrombocytopenia as the least common form of bicytopenia seen in $5.5 \%$ cases. $^{2}$

\section{CONCLUSIONS}

Cytopenia is a common haematological problem encountered in clinical practice. It is the presentation of some underlying medical disorder, some of which are primarily haematological. The aetiological spectrum of cytopenia is diverse. This was a five-year retrospective study of 126 children presented as bicytopenia or pancytopenia and for whom bone marrow examination was done.

In our study, commonest clinical feature was pallor. Splenomegaly followed by lymphadenopathy and hepatomegaly were more with bicytopenia while bleeding and rashes were more with pancytopenia.

Megaloblastic anaemia was the commonest aetiology for both bicytopenia and pancytopenia. Acute leukemia was $2^{\text {nd }}$ commonest cause for bicytopenia and hypoplastic marrow for pancytopenia. Although, the haematological parameters are non-specific and show a considerable overlap, they give diagnostic clues and help in planning further investigations.

Bone marrow aspiration and trephine biopsy are important diagnostic tools in evaluating the cases of cytopenia. Both procedures are complementary to each other and help in providing a prompt and precise diagnosis in cases of pancytopenia and bicytopenia.

Data sharing statement provided by the authors is available with the full text of this article at jemds.com.

Financial or other competing interests: None.

Disclosure forms provided by the authors are available with the full text of this article at jemds.com.

\section{REFERENCES}

[1] Perkins SL. Examination of blood and bone marrow. In: Wintrobe's Clinical Haematology. 10 $10^{\text {th }}$ edn. Maryland: Williams and Wilkins 1999:23-32.

[2] Naseem S, Varma N, Das R, et al. Pediatric patients with bicytopenia/pancytopenia: review of etiologies and clinico-haematological profile at a tertiary center. Indian J Pathol and Microbiol 2011;54(1):75-80.

[3] Keisu M, Ost A. Diagnosis in patients with severe pancytopenia suspected of having aplastic anemia. Eur J Haematol 1990;45(1):11-3.

[4] Bhatnagar SK, Chandra J, Narayan S, et al. Pancytopenia in children: etiological profile. J Trop Pediatr 2005;51(4):236-9.

[5] Niazi M, Fazl-i-Raziq. The incidence of underlying pathology in pancytopenia: an experience of 89 cases. JPMI 2004;18(1):76-9.

[6] Gupta N, Kumar R, Khajuria A. Diagnostic assessment of bone marrow aspiration smears, touch imprints and trephine biopsy in non-hematological disorders. JK Science 2010;12(3):130-3.

[7] Khodke R, Marwah S, Buxi G, et al. Bone marrow examination in cases of pancytopenia. J Indian Acad Clin Med 2001;2:55-9.

[8] Ayub J, Khan FUR. Study on prevalence of megaloblastic anemia in a pediatric unit. Gomal J Med Sci 2009;7(1):624.

[9] Verma N, Malik H, Sharma V, et al. Etiology of pancytopenia in and around Meerut. Journal of Advance Research in Biological Sciences 2012;4(2):145-51.

[10] Javalgi AP, Dombale VD. Clinico-hematological analysis of pancytopenia: a bone marrow study. Natl J Lab Med 2013;2(4):12-7.

[11] Gayathri BN, Rao KS. Pancytopenia: a clinic hematological study. J Lab Physicians 2011;3(1):15-20. 
[12] Negi G, Chandra H, Shirazi N, et al. Pancytopenia: a hospital based study of causes and role of bone marrow examination. Indian Medical Gazette 2011:211-4.

[13] Memon S, Shaikh S, Nizamani MAA. Etiological spectrum of pancytopenia based on bone marrow examination in children. J Coll Physicians Surg Pak 2008;18(3):163-7.

[14] Gupta V, Tripathi S, Tilak V, et al. A study of clinicohaematological profiles of pancytopenia in children. Trop Doct 2008;38(4):241-3.

[15] Jha A, Sayami G, Adhikari RC, et al. Bone marrow examination in cases of pancytopenia. JNMA J Nepal Med Assoc 2008;47(169):12-7.
[16] Gupta V, Tripathi T, Singh TB, et al. A study of bone marrow failure syndrome in children. Indian J Med Sci 2008;62(1):13-8.

[17] Chhabra A, Chandar V, Patel A, et al. Clinico-aetiological profile of pancytopenia in pediatric practice. J Indian Acad Clin Med 2012;13(4):282-5.

[18] Jan AZ, Zahid B, Ahmad S, et al. Pancytopenia in children: a 6-year spectrum of patients admitted to Pediatric Department of Rehman Medical Institute, Peshawar. Pak J Med Sci 2013;29(5):1153-7. 